\title{
Research on the Strategy of Introducing High-level Overseas Talents by Local Government
}

\author{
Na Wei \\ Shandong Xiehe University, Jinan, Shandong, 250107
}

Keywords: Local government; overseas high-level talents; optimization countermeasures

\begin{abstract}
The effective introduction of high-level talents is conducive to promoting the continuous development of economy, society and science and technology, and guiding talents in the process to combine local environmental and ecological construction development and development, and provide constructive suggestions for the development of local governments. Therefore, it is necessary to formulate a talent introduction program suitable for social development in response to local economic characteristics, which is conducive to the development and reform of local governments. This paper analyzes the purpose of local government to introduce talents, and proposes optimal strategies for sustainable development based on the status quo of development.
\end{abstract}

\section{Introduction}

The effective introduction of advanced management methods and management views is conducive to the development and construction of the public sector, and in the process of guiding the city to the development of strategic, development, and technological development, to achieve innovation and development in line with the continuous development of science and technology. Especially in the development and construction of the "new normal", high-quality talents are required to carry out reforms and innovations in combination with the actual situation, so as to optimize the problems in the face of development.

\section{The connotation and value of overseas high-level talents}

\subsection{Connotation}

The connotation of overseas high-level talents is mainly reflected in its special learning background, life background or work background, and highly educated talents with a master's degree or above. At the same time, talents have high-directional skill orientation and professional technical theory, or The talents with profound insights or achievements in a certain study; the most important thing is that the talents are overseas Chinese or domestic students, and can use their theoretical level and practical level to drive the development of China's economy.

\subsection{Value}

"Opening up to the outside world" is one of China's basic national policies. Therefore, the introduction of high-quality, high-tech, high-professional talents is conducive to continuous innovation in China's current science and technology, management model. At the same time, high-quality talents drive the innovative ideas of grassroots personnel, and can continuously optimize the defects in development in the process of perfecting the basic ideas. In addition, the development of national economic technology requires relevant technical personnel to continuously deepen technical literacy while creating strategic goals applicable to national development, so as to ensure that local governments can solve problems in the face of multi-directional development problems. Optimization and resolution.

\subsubsection{Improve the quality of talents}

The progress of society is inseparable from the expansion of high-quality talents and innovative technologies. Therefore, the introduction of high-quality talents is conducive to improving the 
overall quality of personnel, and in the process of changing the core concept of government personnel, so that the grassroots government can continue to improve the basic system under the guidance of high-quality talents. At the same time, it is conducive to continuously deepening the concept of individualized talents, enabling high-quality talents to promote the improvement of the moral concepts and practical concepts of the grassroots departments as a whole, thereby expanding the awareness of the initiative of the grassroots departments and making the departmental atmosphere in a high-quality competitive atmosphere. Ensure the continuous improvement of the overall quality of personnel.

\subsubsection{Improve the infrastructure}

Due to the contradictory nature of the traditional grassroots human resources structure, the division of functions, departmental responsibilities, and professional concepts in the grassroots departments are unreasonable. Therefore, it is necessary for high-quality talents to integrate and divide the structure of the functions of the basic departments, so that the distribution of departmental responsibilities is rational and optimized. At the same time, high-quality talents can be reformed from the basic contradictions, so that the industry composition and professional composition of the grassroots departments are more evenly distributed. Enable talents to achieve optimal distribution of core ideas.

Due to the low quality of the grassroots departments, the basic technical concepts of the department are not innovated, so that the management level and technology level of the grassroots government cannot be improved. Therefore, high-quality people can comprehensively drive the level of scientific and technological innovation, and gradually improve the city's economic efficiency and productivity in the process. At the same time, high-quality talents can provide development for the level of scientific and technological innovation, enable the production technology and management technology of the grassroots departments to be innovatively developed, and promote the overall economic development and scientific progress of the region.

\section{The main problems of local governments introducing high-level talents from the open sea}

In the search for the solution of local problems, the relevant departments did not proceed from the coordination of basic issues. Only paying attention to the fundamental pursuit of the merits and qualifications of famous schools, but not examining whether the construction of talents, the direction of management and the direction of existing problems are consistent, leading to the introduction of talents can not solve the social problems of local diversification. In particular, the relevant departments do not pay much attention to the investigation of talent orientation, and only pay attention to the introduction of skilled talents, so that the local development problems are not in harmony with the research direction of talents, and the actual problems are still not resolved.

At this stage, the government departments vigorously provide social security for technical personnel, especially the establishment of strict system norms, so that high-level overseas welfare benefits are guaranteed. However, some governments have not managed the management and refinement of talents, resulting in the excessive pursuit of the introduction of core talents and neglecting the social security of the original technical talents. Over time, it will induce communication conflicts between old employees and new employees. In particular, the phenomenon of "wearing small shoes" by new employees to new employees has occurred, which not only causes problems in information exchange between the two sides, but also greatly dampens the enthusiasm of the old employees. Reduce employee awareness of government departments [1]. At the same time, due to the deviation of the working methods, living habits, basic concepts and employees of overseas employees, the unsuitable life problems will also lead to social problems and team problems, which will lead to negative cooperation concepts in the foundation of the big environment. Breeding is not conducive to the improvement of overall economic efficiency.

Due to the lack of environmental problems, equipment problems, and information resources in the grassroots departments, the development coordination of overseas high-level talents is not high, especially in some construction directions that deviate from the government's development goals. In 
addition, the government departments have less basic training on talents, so that talents do not understand the core ideas of party building and socialism, and the professionalism of talents cannot be improved. The use value of talents lacks practical significance, which leads to the inability of talents to formulate comprehensive development plans and development goals in line with the long-term development of the government, resulting in the long-term development of talents that cannot be fully coordinated with the society.

The effective introduction of overseas high-level talents is conducive to changing the basic style of government agencies, and continuously constructs a government service concept in the process, so that local governments can promote good party building style and service style construction according to local cultural awareness, and then promote society. Development and construction. Therefore, high-level talents need to be continuously improved:

Work style. Both the grassroots government staff and high-level technical management personnel should establish a high standard of work style and improve the overall concept in the process. At the same time, the government staff in the work with a sense of service with a high sense of responsibility, so that the government's work is continuously integrated into the sense of social crisis and the urgency of grassroots work. In turn, the overseas high-level personnel can integrate thinking in the management process according to the problems existing in the current stage of construction, and explore a better work direction [2]. In addition, relevant personnel are required to have a high standard of operation concept and operation technology while improving the basic style, so that high-level overseas personnel can deepen their efforts in a diligent and hard working style in dealing with different work problems.

Learning style. Overseas high-level personnel must continue to learn and innovate while improving the service concept, and establish a sustainable development thinking in the process. To enable overseas high-level personnel to pay attention to the basic details in the service management, and constantly find problems, plan problems and improve problems in the details. At the same time, in the development of the local construction, it is necessary to pay attention to the actual operation [3], and gradually develop a careful living habit. In the process of learning, high-level overseas personnel need to continuously build a work system that strives for perfection, and explore ways to optimize management methods and innovative methods, and build a sound learning style in the continuous improvement of practical operational concepts.

Up thinking. High-level overseas personnel need a sound service aim, and continue to explore in work and study, so that innovative ideas are integrated into management and development. Therefore, overseas high-level personnel can maintain an upward thinking in the face of development difficulties and management difficulties, and constantly improve their work level and work skills according to the basic service concept, so that the local technology can continue to develop the professional technology of new information technology. To promote the government's positive solutions in the face of diversified urban issues, rural issues, personnel issues, and development issues.

Innovative ideas. Overseas high-level personnel can formulate sustainable development service concepts based on advanced foreign management programs and combined with current social problems, and make full use of foreign management programs for reform and innovation, so as to achieve continuous development and continuous construction of social problems [ 4]. At the same time, overseas high-level personnel can sum up the rules according to the current state of the government, so that the government's development has high-tech innovative management methods and management techniques. In turn, it helps overseas high-level personnel to break through the traditional management concept construction, so that the work is carried out in the construction of the system.

Government departments must conduct innovative research on the construction of basic policies, so that overseas high-level talents have a strong sense of atmosphere, responsibility and security in government work. Therefore, the government must innovate on the optimized talent management methods, and ensure the basic rights and interests of talents in the process, so that the sense of belonging of talents can be improved in the system. 
For example, high-level departments can assign and coordinate work for spouses of overseas high-level personnel, and ensure the satisfaction and happiness of overseas high-level personnel in the system. In particular, managers who have made outstanding contributions to government departments can give priority to spouse work. The deployment method will further ensure that the spouses of overseas high-level personnel have a stable job; at the same time, it is necessary to optimize the allocation of their children's schools, so that the children of overseas high-level personnel can enjoy a high standard of education and learning environment, and then In the system, the basic interests of overseas high-level personnel are guaranteed to be perfected in the practice of policies.

The senior leadership departments must deepen the capital investment in the government's scientific management technology and scientific and innovative technologies, so that high-level overseas personnel can improve infrastructure and management software in the control of financial support, so that the government's development and construction can be high. Standard, high-tech technology is improved [5]. The local agriculture and industry will continue to develop in policy support, helping the government to build a streamlined human resource development system.

At the same time, it is necessary to carry out visual risk control for the department, so that scientific progress is built into the visual reward. Therefore, the government must strengthen cooperation and exchanges with risk pre-control companies, so that the development and construction of overseas high-level personnel has a long-term return meaning, and then expand the sense of responsibility and trust in urban construction, and guide the government to support the policy. Standardized and rapid development.

Local governments need to pay more attention to the exploration of social issues in the direction of improving drainage, so as to ensure that the direction of talents has direct and directional goals, and promote local development and construction to adapt to the environment. Therefore, it is necessary to subdivide the professionalism of talents and the direction of talents, and to screen talents according to scientific management software, so that talents can give full play to their advantages in the face of diversified social development. In addition, it is necessary to pay attention to the analysis and research on the subjective will of overseas high-level personnel, so that the construction of talents can have the optimal state that can adapt to the development of society in the construction of scientific development, and thus ensure the coordinated development of local urbanization development. Economic benefits, in order to achieve the optimization of social benefits.

Senior staff must strengthen the development of teamwork and team communication skills, so that employees can have a directional goal in the integration of system construction. At the same time, it is necessary to organize relevant management personnel to carry out group building activities so that the emotional barriers between employees can be broken through in communication. In addition, a symposium to optimize team building can be carried out to deepen the principle of consistency of team thinking. Therefore, it is necessary to establish a reasonable management system in the compensation system, promote the team's fairness and competitive synergy development, and then optimize the dynamic characteristics of government management work, and satisfy employees' pursuit of work happiness.

The government department must train and construct the sustainable development of the personnel, and continuously guide the relevant technical personnel to develop and explore the high-standard technical plan in the process. At the same time, relevant departments must introduce a directional technical training organization, so that the core concept of employees can continue to innovate in the process of training and configuration, and help overseas high-level personnel to face reform and innovation in the face of different social problems [6]. In addition, it is necessary to improve the basic goal planning, so that the moral literacy and basic theory of personnel will be developed in a coordinated manner in the training process, which will promote the fundamental improvement of regional economic efficiency. 


\section{Conclusion}

The innovative construction of local governments is inseparable from the construction and awareness of sustainable development consciousness, and continuously introduces high-quality overseas high-level talents in the process to face different problems in development and formulate solutions in a timely manner. This not only has a guiding and promoting effect on economic development, but also helps local governments to continuously reform in line with the progress of the times, thereby improving the economic level and economic benefits of local regions.

\section{Acknowledgements}

The sixth batch of projects of science and technology development plan of Jinan in 2018(soft science plan, Project name: Research on the long-acting mechanism of indoctrination based on demand orientation in JiNan province, Project No.: 201806003

\section{References}

[1] Yin Jiazhen, Deng Mengxi. Innovative Research on Local Government's Policy of Introducing Overseas High-level Talents___Taking Guangxi Zhuang Autonomous Region as an Example[J]. Human Resources Development, 2017(12):7-9.

[2] Yang Qing. Research on the evaluation and promotion of overseas high-level talent introduction efficiency [D]. Tianjin University, 2017.

[3] Wang Ruilong. Research on the problems and countermeasures of China's overseas high-level talent service institutions [D]. Beijing Jiaotong University, 2015.

[4] Miu Yuquan. Research on the introduction of overseas high-level talents in local governments in China [D]. Nanjing University, 2016.

[5] Hu Xiaoqiong. Reflections on the introduction of talents by local governments under the perspective of coordinated development [J]. Heihe Academic Journal, 2017(4): 24-25.

[6] Sun Meijia, HU Wei. Research on the Influence of Government Administrative Efficiency on High-level Talents Agglomeration[J]. Journal of Jiangsu Administration Institute, 2016(5): 117-122. 